\title{
THE EFFICACY OF NEODYMIUM:YAG LASER IRIDOTOMY IN THE TREATMENT OF CLOSED PERIPHERAL IRIDOTOMIES IN SILICONE-OIL-FILLED APHAKIC EYES
}

\author{
M. A. REDDY and G. W. AYLWARD \\ London
}

\begin{abstract}
SUMMARY
Eighteen patients had a surgical inferior peripheral iridotomy performed to prevent pupil block and silicone oil anterior chamber prolapse. The occlusion of an iridotomy was treated by neodymium:YAG laser therapy and this form of treatment was successful only in 4 cases $(22 \%)$. The reopening of occluded iridotomies is best performed by surgery as opposed to laser treatment.
\end{abstract}

The intraocular injection of silicone oil is frequently used in the management of complex retinal detachments. ${ }^{1}$ The advantage of silicone oil in producing permanent tamponade is balanced by its complications. ${ }^{2}$ Hence, removal of silicone oil is desirable once secure retinal reattachment is achieved. In aphakic eyes, the main complications of silicone oil are glaucoma and keratopathy. ${ }^{3}$ The evolution of the keratopathy is dependent upon contact between silicone oil and the corneal endothelium. ${ }^{4}$ Therefore the presence of silicone oil in the anterior chamber (AC) of aphakic eyes should be avoided. Prolapse of oil into the $\mathrm{AC}$ occurs secondary to pupil block, ${ }^{5}$ which does not occur if the flow of aqueous is facilitated by a peripheral iridotomy (PI).

Inferior iridotomies have been shown to be effective when performed at the same time as silicone oil injection in aphakic eyes. ${ }^{6}$ Superior PIs are particularly suitable in patients requiring cataract surgery after previous vitrectomy and silicone oil surgery. ${ }^{7}$ If the PI is not patent, oil will fill the AC, requiring a repeat surgical iridotomy or laser iridotomy. Neodymium:YAG laser iridotomy has the advantage over surgical iridotomy of being an

Correspondence to: Mr G. W. Aylward, Vitreoretinal Unit, Moorfields Eye Hospital, London EC1V 2PD, UK. outpatient procedure. In addition, the rates of complications such as ciliary block glaucoma and intraocular infection are reduced.8,9 This study examines the effectiveness of neodymium:YAG PI in the treatment of blocked inferior iridotomies.

\section{PATIENTS AND METHODS}

The case-notes of all patients who had undergone vitrectomy and fluid/silicone oil exchange in Moorfields Eye Hospital between January 1990 and December 1994 were reviewed. Indications for silicone oil included giant retinal tears (GRT), proliferative vitreoretinopathy (PVR) following rhegmatogenous retinal detachment or penetrating trauma and proliferative diabetic retinopathy (PDR). Patients were identified who fulfilled the criteria of aphakia with a failed inferior peripheral iridotomy, and had been treated with neodymium:YAG laser. All the initial surgical PIs were performed inferiorly. In all cases, laser energy was delivered through an Abrahams contact lens, using four pulses per burst with no defocus. Power settings ranged from 1.0 to $8.4 \mathrm{~mJ}$.

\section{RESULTS}

There were 18 patients ( 9 men and 9 women) of average age 45.5 years (range $21-70$ years). Four patients were treated for PDR, 11 for PVR and 3 presented with GRTs. The patients with PVR included 3 with the following associated pathological conditions: penetrating trauma, retinal vasculitis and melanoma. There was one intracapsular cataract extraction and one pars plana lensectomy following initial silicone oil injection. Sixteen patients had pars plana lensectomies performed at the same time as silicone oil insertion. All iridotomies, including postinjection iridotomies, were performed inferiorly in this series. The initial surgical PI became occluded 


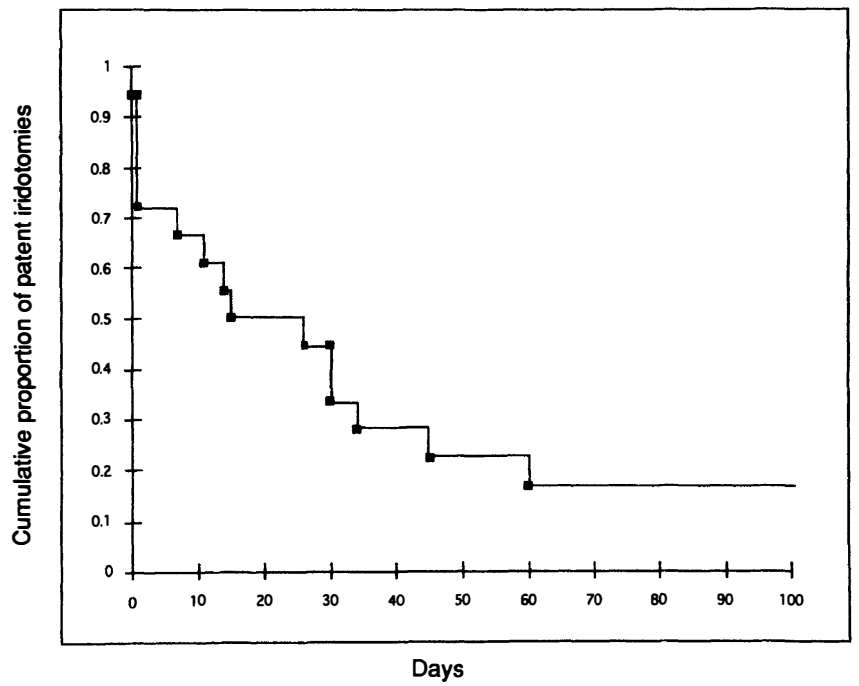

Fig. 1. Life table analysis showing survival of patent iridotomies after treatment with neodymium:YAG laser.

after an average of 77.1 days (range 1 day to 16 months).

The number of eyes in which the PI was successfully reopened by neodymium:YAG laser treatment was $4(22 \%)$. These eyes had PIs that remained patent at last follow-up and consisted of patients with GRTs (2), PVR and PDR.

The probability of the reopened PI remaining patent is shown by the Kaplan-Meier survival curve in Fig. 1. The curve shows that after an interval of 15 days, the probability of remaining patent has fallen to $50 \%$. Table I shows that 8 patients $(44 \%)$ had more than one laser procedure in order to reopen the closed iridotomy. Of the eyes requiring more than one YAG iridotomy, 2 (25\%) remained patent at final follow-up.

\section{DISCUSSION}

The results of this study suggest that neodymium:YAG iridotomy is unhelpful in the management of blocked surgical inferior PIs in aphakic eyes filled with silicone oil. Neodymium:YAG laser iridotomies for acute angle closure glaucoma are less effective than surgical PIs, being more likely to close. $^{10}$ The success rates are nevertheless much more acceptable than those in our study. Why should neodymium:YAG laser iridotomy be so ineffective in the silicone-oil-filled eye?

In a fluid-filled $\mathrm{AC}$, the debris and blood resulting from a burst of laser energy is able to disperse throughout the $\mathrm{AC}$, thus allowing a further burst. Any haemorrhage from a laser burst in silicone-oilfilled ACs is held against the target site by the oil, with which it is immiscible, and does not disperse. In practice this makes a second burst of laser at the same site impractical. Despite using four pulses per burst, a PI was not created in $2(6.5 \%)$ procedures. Even if a patent PI was achieved, in most cases a
Table I. Patency of peripheral iridotomy at last follow-up

\begin{tabular}{lcc}
\hline $\begin{array}{l}\text { No. of } \\
\text { YAG procedures }\end{array}$ & $\begin{array}{c}\text { Patent iridotomy } \\
\text { (no. of eyes) }\end{array}$ & $\begin{array}{c}\text { Closed iridotomy } \\
\text { (no. of eyes) }\end{array}$ \\
\hline 1 & 2 & 8 \\
2 & 2 & 1 \\
3 & - & 5 \\
\hline
\end{tabular}

further burst to enlarge the PI was not possible. Therefore most PIs produced by laser were small and thus more prone to close. The process of closure was no doubt enhanced by the lack of dispersion of blood and debris from the PI.

Silicone oil is known to absorb little or no light in the visible range of the spectrum ${ }^{11}$ and absorption of neodymium:YAG laser (with a long wavelength of $1060 \mathrm{~nm}$ ) by silicone oil is not thought to contribute to the poor efficacy of laser therapy. Hence, silicone oil does not actually absorb energy. However, the neodymium:YAG laser acts by convergence of rays onto a focal point. ${ }^{12}$ The refractive properties of silicone oil may affect spot size and the energy per area delivered to the iris. In conclusion, laser therapy was not effective in reopening inferior PIs in $77.8 \%$ of cases reviewed, probably secondary to the presence of silicone oil in the AC. Laboratory tests involving the analysis of neodymium:YAG laser spot size in different fluids would be of considerable value. Occluded PIs in silicone-oil-filled aphakic eyes result in oil-filled ACs and consequent oil/endothelial contact. Prompt treatment is required to avoid corneal complications. The results of this study show that neodymium:YAG laser is a temporary solution at best. We recommend that a large surgical PI is the definitive treatment of this eventuality in eyes in which the removal of oil is not desired.

We would like to thank Professor Marshall for his assistance in the discussion section of this paper.

Key words: Aphakia, Iridotomy, Pupil block, Silicone oil, YAG laser.

\section{REFERENCES}

1. Lucke K, Laqua H. Silicone oil in the treatment of complicated retinal detachments. Berlin: Springer, 1990:1-7.

2. Riedel KG, Gabel V, Neubauer L, Kampic A, Lund O. Intravitreal silicone oil injection: complications and treatment of 415 consecutive patients. Graefes Arch Clin Exp Ophthalmol 1990;228:19-23.

3. Laganowski HC, Leaver PK. Silicone oil in the aphakic eye: the influence of a six o'clock peripheral iridectomy. Eye 1989;3:338-48.

4. Beekhuis WH, van Rij G, Zivojnovic R. Silicone oil keratopathy: indications for keratoplasty. $\mathrm{Br} J$ Ophthalmol 1985;69:247-53.

5. Ando F. Intraocular hypertension resulting from pupillary block by silicone oil. Am J Ophthalmol 1985;99:87-8.

6. Beekhuis WH, Ando F, Zivojnovic R, Mertens DAE, Peperkamp E. Basal iridectomy at 6 o'clock in the aphakic eye treated with silicone oil: prevention of 
keratopathy and secondary glaucoma. Br J Ophthalmol 1987;71:197-200.

7. Elliott AJ, Bacon AS, Scott JD. The superior peripheral iridectomy: prevention of pupil block due to silicone oil. Eye 1990;4:226-9.

8. Morsman CDG. Acute glaucoma in the presence of patent neodymium:YAG laser iridotomies. Acta Ophthalmol (Copenh) 1991;69:68-70.

9. Brazier DJ. Neodymium-YAG laser iridotomy. J R Soc Med 1989;79:658-60.

10. Buckley SA, Reeves B, Burdon M, Moorman C,
Wheatcroft S, Edelsten C, Benjamin L. Acute angle closure glaucoma: relative failure of YAG iridotomy in affected eyes and factors influencing outcome. $\mathrm{Br} \mathrm{J}$ Ophthalmol 1994;78:529-33.

11. Azzolini C, Docchio F, Brancota R, Tranbucci G. Interactions between light and vitreous fluid substitutes. Arch Ophthalmol 1992;110:1468-71.

12. Sigelman J. Retinal diseases: pathogenesis, laser therapy, and surgery, 1st ed. Boston: Little, Brown, 1984:90-3. 